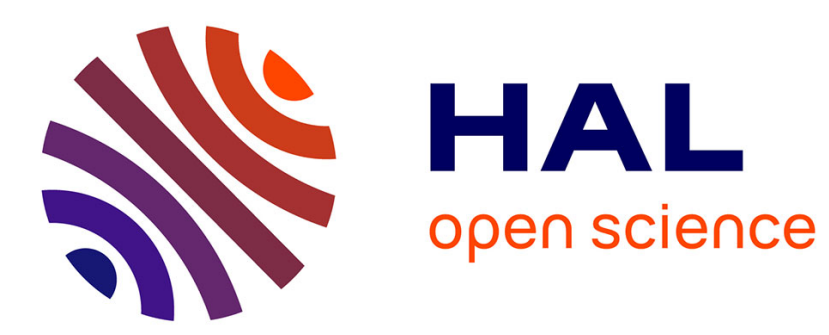

\title{
User-friendly software for vector analysis of the magnetization of long sediment cores
}

\author{
A. Mazaud
}

\section{To cite this version:}

A. Mazaud. User-friendly software for vector analysis of the magnetization of long sediment cores. Geochemistry, Geophysics, Geosystems, 2005, 6 (12), pp.n/a-n/a. 10.1029/2005GC001036 . hal03118278

\section{HAL Id: hal-03118278 \\ https://hal.science/hal-03118278}

Submitted on 18 Feb 2021

HAL is a multi-disciplinary open access archive for the deposit and dissemination of scientific research documents, whether they are published or not. The documents may come from teaching and research institutions in France or abroad, or from public or private research centers.
L'archive ouverte pluridisciplinaire HAL, est destinée au dépôt et à la diffusion de documents scientifiques de niveau recherche, publiés ou non, émanant des établissements d'enseignement et de recherche français ou étrangers, des laboratoires publics ou privés. 


\title{
User-friendly software for vector analysis of the magnetization of long sediment cores
}

\author{
A. Mazaud \\ Laboratoire des Sciences du Climat et de l'Environnement, CEA-CNRS, Domaine du CNRS, 91198 Gif-sur-Yvette, \\ France (mazaud@lsce.cnrs-giff.fr)
}

[1] New software is described that is designed for easy visualization and treatment of stepwise demagnetization of the natural remanent magnetization measured along sediment cores with pass-through magnetometers. The software displays demagnetization diagrams (Zijderveld plots) at successive horizons for any depth interval selected by the user. Paleomagnetic directions are automatically calculated using principal component analysis, with an anchored or a free origin. The demagnetization steps to be considered for the diagram visualization and paleodirection calculations are selected by the user. Maximum angular deviation angles and median destruction fields are also calculated. All the results are stored in a single data sheet, which can be easily exported. Demagnetization diagrams can be printed and copied. This Microsoft Excel software can be used by PC or Macintosh microcomputers.

Components: 2491 words, 2 figures, 2 tables, 2 datasets.

Keywords: analyses; core; magnetization; vector.

Index Terms: 1594 Geomagnetism and Paleomagnetism: Instruments and techniques.

Received 2 June 2005; Revised 22 July 2005; Accepted 28 October 2005; Published 23 December 2005.

Mazaud, A. (2005), User-friendly software for vector analysis of the magnetization of long sediment cores, Geochem. Geophys. Geosyst., 6, Q12006, doi:10.1029/2005GC001036.

\section{Introduction}

[2] High-resolution measurements of sediment cores with a pass-through cryogenic magnetometer generate in relatively short times a large amount of data that need to be analyzed to determine the characteristic remanent magnetization (ChRM) directions along the sediment column. The technique of long core measurements, initially proposed by Goree and Fuller [1976], is now widely used, together with u-channel samples that were initially proposed by Tauxe et al. [1983] and subsequently improved at Gif-sur-Yvette [Weeks et al., 1993].

[3] New software has been developed for rapid and easy visualization and treatment of natural remanent magnetization (NRM) demagnetization diagrams (Zijderveld plots [Zijderveld, 1967]) for any depth interval selected by the user. Optimal selection of suitable demagnetization steps allows inclusion, or rejection, of data for any alternating field (AF) step used for demagnetization. Thus, different demagnetization steps can be selected for different depth intervals in a core. An option allows automatic printing of successively displayed demagnetization diagrams. The program saves the calculated ChRM directions, which are calculated using a principal component analysis (PCA) routine, with an anchored or a free origin for the best-fit line. The maximum angular (MAD) deviation of the fit [Kirschvink, 1980] and the median destructive field (MDF) of the NRM are also calculated. The last demagnetization diagram displayed during a run can be copied to enable transfer to other drawing software packages. Declination and inclination and MAD values of the best-fit ChRM, and MAD and MDF values are recorded in 
Table 1. The "Data" Sheet"

\begin{tabular}{|c|c|c|c|c|c|c|c|c|c|c|c|}
\hline & A & B & $\mathrm{C}$ & $\mathrm{D}$ & E & $\mathrm{F}$ & $\mathrm{G}$ & $\mathrm{H}$ & I & $\mathrm{J}$ & $\mathrm{K}$ \\
\hline 1 & Index & int, $\mathrm{mT}$ & int, $\mathrm{mT}$ & int, $\mathrm{mT}$ & int, $\mathrm{mT}$ & int, $\mathrm{mT}$ & int, $\mathrm{mT}$ & int, mT & int, mT & int, $\mathrm{mT}$ & int, $\mathrm{mT}$ \\
\hline 2 & & 0 & 5 & 10 & 15 & 20 & 25 & 30 & 35 & 40 & 45 \\
\hline$\cdots \cdot$ & $\cdots$ & $\cdots \cdot$ & $\cdots$ & $\cdots$ & $\cdots$ & $\cdots$ & $\cdots$ & $\cdots$ & $\cdots$ & $\cdots$ & $\cdots$ \\
\hline 1004 & 20004 & 202925.4 & 95725.6 & 62059.6 & 3645 & 3742 & 298 & 243 & 199 & 166 & 13461 \\
\hline 1005 & 20005 & 717 & 10564 & 65 & 5 & 42 & 34 & 275 & 2 & 9 & 5423. \\
\hline 1006 & 20006 & 22802 & 10364 & 6 & 510 & 40 & 33 & 4 & 222 & & 38 \\
\hline 1007 & 20007 & 240380.8 & 92830.3 & 57 & 428 & 3429 & 2805 & 22 & 1880 & .7 & 13067.8 \\
\hline 1008 & 20008 & 258055.8 & 81309 & 9 & 33 & 2660 & 21 & 0.1 & 14 & 12 & 10492.8 \\
\hline 1009 & 20009 & 279219.4 & 76053.2 & 38490.7 & 28370.2 & 22897.4 & 18879.1 & 15591.6 & 13126.4 & 11147.8 & 9572.2 \\
\hline 1010 & 20010 & 300416.4 & 76986.2 & 39912.9 & 31315.5 & 25505.5 & 21717.8 & 18291.6 & 15207.6 & 13271.5 & 11101.9 \\
\hline 1011 & 20011 & 321635.5 & 82334 & 48530.7 & 40237.4 & 33491.8 & 28775.4 & 24145.9 & 20217.3 & 17455.5 & 14499 \\
\hline 1012 & 20012 & 342172.3 & 90658.3 & 62143.8 & 52936.6 & 44753.4 & 38119.1 & 31963.5 & 26869.5 & 23014.9 & 18927.4 \\
\hline 101 & 20013 & 360978 & 99651.5 & 7606 & & 5613 & & & & & 23432.2 \\
\hline 1014 & 20014 & 375288.5 & 106723.4 & 86529.4 & 74812.4 & 64436.3 & 53980.1 & 45273.4 & 38004.2 & 32509.7 & 27085.3 \\
\hline
\end{tabular}

\footnotetext{
${ }^{\mathrm{a}}$ Intensities must be entered in columns B to $\mathrm{U}$. Corresponding declinations and inclinations must be entered in columns $\mathrm{X}$ to AQ, and AT to $\mathrm{BM}$, respectively. The peak values of the alternating field (AF) demagnetization must be indicated in line 2. Column A can be used as a data index (e.g., depth of the horizon in the core).
}

columns in an output worksheet. The software is in the form of a Microsoft Excel file, which can be used by PC or Macintosh microcomputers. Although it is specifically designed for analysis of NRM demagnetization, it can be also used for calculating the MDF of the anhysteretic remanent magnetization and of the isothermal remanent magnetization. This program uses a simple column format that allows easy input/output (auxiliary material ${ }^{1}$ ).

\section{Software Description}

[4] The software consists of a Microsoft Excel file, named "Macro-Uch-1.xls". It includes some macro-commands, which should not be modified, and several sheets for data input, visualization, and result storage. The various sheets of interest to the user are named "Data", "Command", "Graph Zij" and "Results". Two additional sheets, named "C-1" and "C-2", are used for calculations. The "C-1" and "C-2" sheets should not need to be modified. It is recommended to make one or two back-up copies of the program file "MacroUch-1.xls" before first use.

\section{1. "Data" Sheet}

[5] The "Data" sheet is designed to accommodate a maximum of 20 demagnetization steps. Column A is not used for any calculations. It can be used for indexing the data, either by depth or by any

\footnotetext{
${ }^{1}$ Auxiliary material is available at $\mathrm{ftp}: / / \mathrm{ftp}$.agu.org/apend/gc/ $2005 \mathrm{GC} 001036$
}

other label. Intensity data obtained for the different demagnetization steps must be entered in columns $\mathrm{B}$ to $\mathrm{U}$. For each column, the peak value of the AF demagnetization step must be indicated in row 2 (Table 1). Then, measured declinations must be entered in columns $\mathrm{X}$ to AQ. The peak value of the alternating field (AF) is automatically displayed in row 2, which is identical to the respective values given in the respective intensity columns (columns $\mathrm{B}$ to $\mathrm{U}$ ). Inclinations must be entered in columns AT to BM. The maximum length for the column data is that of Microsoft Excel, which is adequate to process large data sets.

\section{2. "Command" Sheet}

[6] Different parameters must be entered in the "Command" sheet (Figure 1) before starting a calculation. The first two parameters are the starting and ending line numbers in the data spreadsheet for which calculations and results will be displayed. Then the demagnetization steps used for display and calculations must be selected. All of the demagnetization steps previously indicated in the "Data" sheet are displayed in column A of the "Command" sheet (lines 8 to 27). To select or discard one demagnetization step, enter 1 or 0 in column B, in the line where the step value appears in column A. A zero should be entered for any demagnetization step appearing in the list for which no measurements exist in the considered interval (Figure 1).

[7] The user must then document several options. A value of 1 activates an option, while a value of 


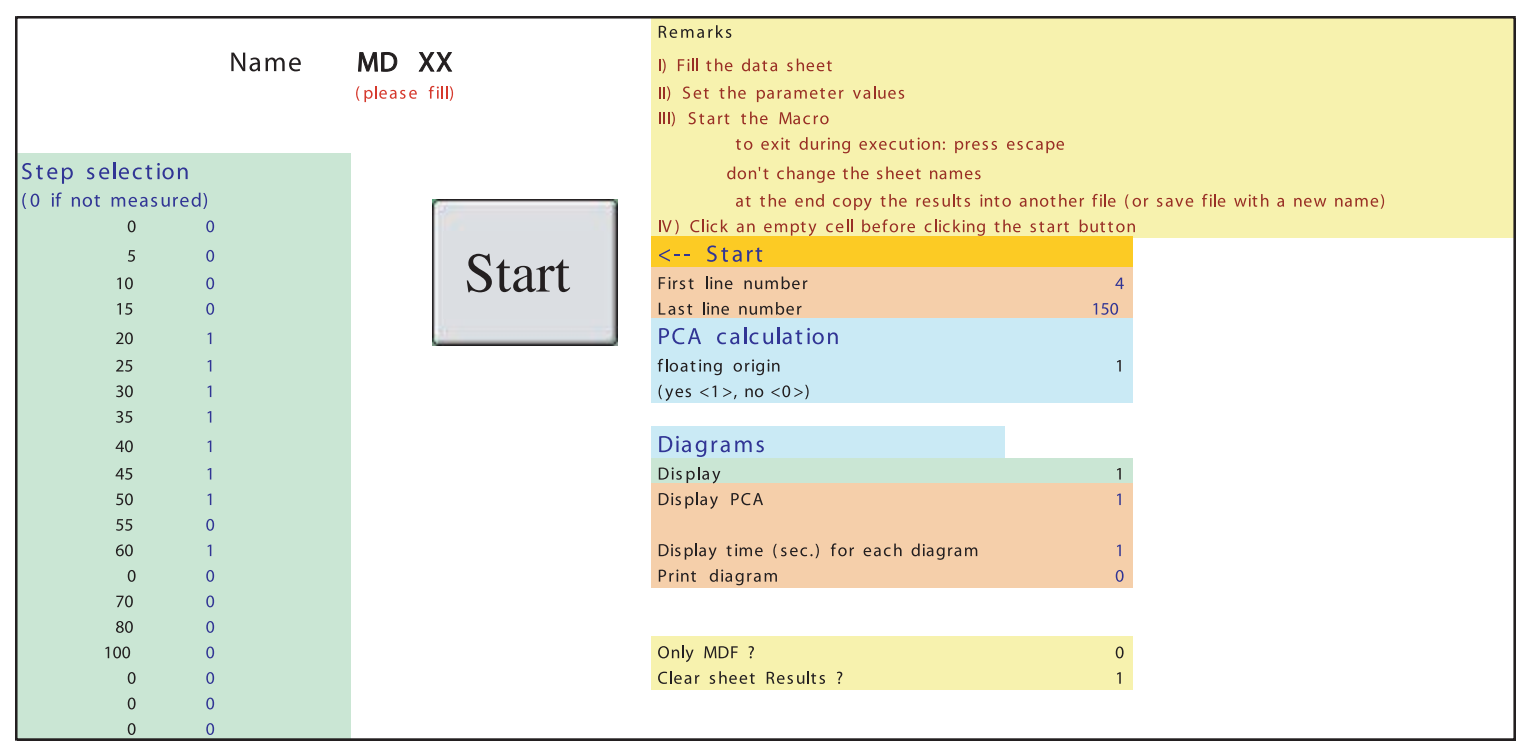

Figure 1. The "Command" sheet. In this example, all the demagnetization steps between 20 and $60 \mathrm{mT}$ are selected, except the step at $55 \mathrm{mT}$. A zero should be entered for any demagnetization step appearing in the list for which no measurements exist in the considered interval. The calculation will begin at line $\mathrm{n}^{\circ} 4$ and end at line $\mathrm{n}^{\circ} 150$. A floating origin will be used (option value set to 1). Display of the demagnetization diagrams is activated. The spacing time between successive diagrams equals here $1 \mathrm{~s}$. The print option is not activated, and the "Results" sheet will be cleared at the start of the calculation.
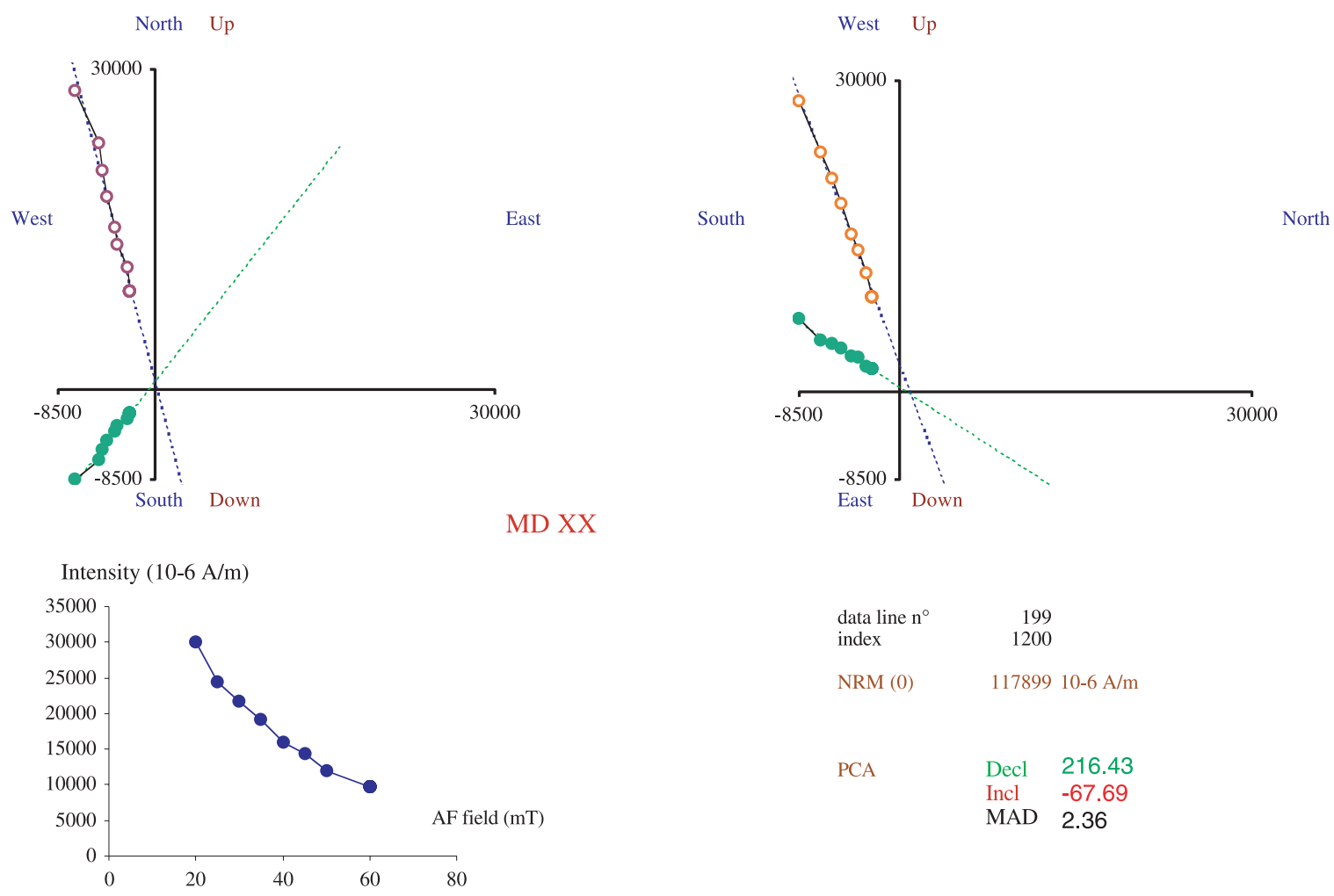

Figure 2. A view of the "Graph Zij" sheet, with the demagnetization diagrams (Zijderveld plots and intensity versus AF demagnetization field). The ChRM direction calculated by PCA is represented in the Zijderveld plots by the dotted lines. The magnetization unit is in this example $10^{-6} \mathrm{~A} / \mathrm{m}$. It can be changed to equal the units of the data entered in the "Data" worksheet. 
Table 2. The "Results" Sheet ${ }^{\mathrm{a}}$

\begin{tabular}{|c|c|c|c|c|c|c|c|c|c|c|c|c|c|c|}
\hline & A & B & $\mathrm{C}$ & $\mathrm{D}$ & E & F & $\mathrm{G}$ & $\mathrm{H}$ & I & $\mathrm{J}$ & K & $\mathrm{L}$ & $\mathrm{M}$ & $\mathrm{N}$ \\
\hline 1 & Index & $\begin{array}{c}\text { Decl } \\
\text { PCA, deg }\end{array}$ & $\begin{array}{c}\text { Incl PCA, } \\
\text { deg }\end{array}$ & $\begin{array}{c}\text { MAD, } \\
\text { deg }\end{array}$ & $\begin{array}{c}\text { MDF, } \\
\mathrm{mT}\end{array}$ & $\begin{array}{l}\text { Steps, } \\
\mathrm{mT}\end{array}$ & 0 & 5 & 10 & 15 & 20 & 25 & 30 & 35 \\
\hline \multicolumn{15}{|l|}{2} \\
\hline$\ldots$ & $\ldots$ & $\ldots$ & $\ldots$ & $\ldots$ & $\ldots$ & & $\cdots$ & $\ldots$ & $\ldots$ & $\ldots$ & $\ldots$ & $\ldots$ & $\ldots$ & . \\
\hline 1004 & $\begin{array}{l}\ldots \\
1006\end{array}$ & 289.05 & $\ldots .5$ & $2^{\cdots}$ & $\begin{array}{l}\ldots . \\
4.1\end{array}$ & & $\ddot{0}$ & $\ddot{0}$ & $\ddot{0}$ & 0 & $\ddot{1}$ & $\ddot{1}$ & $\ddot{1}$ & $\ddot{1}$ \\
\hline 1005 & 1007 & 277.15 & 23.1 & 3.8 & 3.7 & & 0 & 0 & 0 & 0 & 1 & 1 & 1 & 1 \\
\hline 1006 & 1008 & 255.95 & 23 & 6.2 & 3.4 & & 0 & 0 & 0 & 0 & 1 & 1 & 1 & 1 \\
\hline 1007 & 1009 & 237.75 & 14.7 & 6.2 & 3.4 & & 0 & 0 & 0 & 0 & 1 & 1 & 1 & 1 \\
\hline 1008 & 1010 & 232.65 & 5.8 & 4.9 & 3.4 & & 0 & 0 & 0 & 0 & 1 & 1 & 1 & 1 \\
\hline 1009 & 1011 & 233.35 & -0.3 & 3.9 & 3.4 & & 0 & 0 & 0 & 0 & 1 & 1 & 1 & 1 \\
\hline 1010 & 1012 & 233.75 & -4 & 3.2 & 3.5 & & 0 & 0 & 0 & 0 & 1 & 1 & 1 & 1 \\
\hline 1011 & 1013 & 232.85 & -6.2 & 2.9 & 3.5 & & 0 & 0 & 0 & 0 & 1 & 1 & 1 & 1 \\
\hline 1012 & 1014 & 230.95 & -7.8 & 2.8 & 3.5 & & 0 & 0 & 0 & 0 & 1 & 1 & 1 & 1 \\
\hline 1013 & 1015 & 228.35 & -9.8 & 2.8 & 3.5 & & 0 & 0 & 0 & 0 & 1 & 1 & 1 & 1 \\
\hline 1014 & 1016 & 226.25 & -12.2 & 2.9 & 3.5 & & 0 & 0 & 0 & 0 & 1 & 1 & 1 & 1 \\
\hline
\end{tabular}

\footnotetext{
${ }^{\mathrm{a}}$ The "Results" sheet contains the calculated PCA directions (i.e., declination and inclination) of the ChRM, and the MAD and MDF values. Steps selected for the PCA calculation are indicated for the successive horizons in the columns on the right. A value of 1 indicates selection, while a value of zero means that the step was not selected. In this example, steps at $0,5,10$, and $15 \mathrm{mT}$ were not selected (see also Figure 1).
}

zero deactivates it. In the example shown in Figure 1, demagnetization diagram display and PCA calculation will be done for each horizon between lines 4 and 150 in the "Data" sheet. A floating origin is selected for the ChRM direction calculations. Visualization of the demagnetization diagrams is activated, and a time of 1 second separates presentation of the successive diagrams. The print option, which allows direct printing of the successive diagrams, is not activated. Finally, it is also possible to calculate only MDFs, in particular when ARM or IRM are considered. In this case, diagram visualization and PCA calculations can be deactivated. When the option selection is finished, click on any empty cell before clicking the start button, to ensure that all option values are entered (otherwise the calculation will not proceed).

\section{[8] Then, click on the Start button.}

[9] Demagnetization diagrams (Zijderveld plots) for the successive horizons in the selected core interval will be successively displayed (Figure 2). The ChRM directions and the MAD values are calculated automatically and are stored in the "Results" sheet. Intensity changes upon progressive demagnetization are also visualized and MDF values are calculated. The last demagnetization diagram displayed remains in the "Graph Zij" sheet after completion of the program execution, so that it can be copied, printed, or exported. Magnetization units are $10^{-6} \mathrm{~A} / \mathrm{m}$ in the "Graph Zij" sheet. The units can be changed to those for the data entered in the "Data" worksheet. The display size of the demagnetization diagrams can be adjusted before or after any run by choosing an appropriate zoom factor in the display menu of the "Graph Zij” Sheet.

\section{3. "Results" Sheet}

[10] The results are stored in the "Results" sheet (Table 2). The results consist of the declinations and inclinations of the ChRM directions, and the MAD and the MDF values. The "Results" sheet can be cleared, or not, at the beginning of a new calculation (see the "Command" sheet). Thus, previous results can be kept if the ChRM directions are recalculated in a second run over a smaller interval, for instance if a first run suggested that the selection of demagnetization steps should be changed. In this case, only the recalculated lines will be modified. If the clearing option is activated in the "Command" sheet, then the "Results" sheet is entirely cleared at the start of the calculation. An example of a "Results" sheet is given in Table 2. Steps selected for the PCA calculation are indicated for the successive horizons in the columns on the right.

\section{Conclusion}

[11] The purpose of the described program is to facilitate rapid exploitation of the magnetic measurements obtained with pass-through magnetometers for sediment cores. Exploitation can be 
conducted in two steps. First, a few runs allow visualization and printing of demagnetization diagrams obtained with different step selections, which allows informed decisions about the optimal selection of demagnetization steps, and identification of intervals that must be treated separately. The demagnetization step selection can be different for different intervals of the core for optimal determination of ChRM directions, in particular if the magnetic mineralogy or grain size varies along the studied core. ChRM directions and MAD values can be then calculated for each interval of the core. This Excel file can be obtained by request to the author (mazaud@1sce.cnrs-gif.fr). Comments and suggested changes are welcome.

\section{Acknowledgments}

[12] The author thanks Catherine Kissel for suggestions and tests, Vincent Scao for tests, and Andy Roberts and an anonymous reviewer for helpful suggestions. This study was funded by the French Commissariat à l'Energie Atomique (CEA) and the Centre National de la Recherche Scientifique (CNRS). LSCE contribution 1562.

\section{References}

Goree, W. S., and M. Fuller (1976), Magnetometers using R. F. driven squids and their applications in rock magnetism and paleomagnetism, Rev. Geophys., 14, 591-608.

Kirschvink, J. L. (1980), The least square line and plane analysis of palaeomagnetic data, Geophys. J. R. Astron. Soc., 62, 319-354.

Tauxe, L., J. L. La Brecque, R. Dodson, M. Fuller, and J. Dematteo (1983), 'U' channels-A new technique for paleomagnetic analysis of hydraulic piston cores, Eos Trans. $A G U, 64,2-19$.

Weeks, R., C. Laj, L. Endignoux, M. Fuller, A. Roberts, R. Manganne, E. Blanchard, and W. Goree (1993), Improvements in long-core measurement techniques: Applications in palaeomagnetism and palaeoceanography, Geophys. J. Int., $114,651-662$.

Zijderveld, J. D. A. (1967), Demagnetisation of rocks: Analysis of results, in Methods in Palaeomagnetism, edited by D. Collinson et al., pp. 254-286, Elsevier, New York. 